\title{
The role of phonological and executive working memory resources in simple arithmetic strategies
}

\author{
Ineke Imbo and André Vandierendonck \\ Ghent University, Belgium
}

\begin{abstract}
The current study investigated the role of the central executive and the phonological loop in arithmetic strategies to solve simple addition problems (Experiment 1) and simple subtraction problems (Experiment 2). The choice/no-choice method was used to investigate strategy execution and strategy selection independently. The central executive was involved in both retrieval and procedural strategies, but played a larger role in the latter than in the former. Active phonological processes played a role in procedural strategies only. Passive phonological resources, finally, were only needed when counting was used to solve subtraction problems. No effects of working memory load on strategy selection were observed.
\end{abstract}

Being able to solve arithmetic problems mentally (i.e., without using a calculator or a similar device) is a skill that is very useful in daily life. During the past decade, many studies have shown that mental arithmetic relies - among other things - on a well functioning working memory (see DeStefano \& LeFevre, 2004, for review). Although working memory resources might fulfil a role in several subprocesses of the arithmetic problem-solving process (e.g., problem encoding, accessing and searching long-term memory, calculating the correct answer, stating the answer), the current study concentrates on the role of working memory in the processing stages that take place after the problem has been encoded and before the answer is stated.

In these specific processing stages, people might use a variety of strategies to solve the arithmetic problem (e.g., Hecht, 1999; LeFevre, Bisanz, et al., 1996a; LeFevre, Sadesky, \& Bisanz, 1996b). They might retrieve the answer

Correspondence should be addressed to Ineke Imbo, Department of Experimental Psychology, Ghent University, Henri Dunantlaan 2, B-9000 Ghent, Belgium. E-mail: Ineke.Imbo@UGent.be

The research reported in this paper was supported by grant no. 011D07803 of the Special Research Fund at Ghent University to the first author and by grant no. 10251101 of the Special Research Fund of Ghent University to the second author. Thanks are extended to Koen Luwel, Jeff Bisanz, and two anonymous reviewers for their helpful comments on previous drafts of this paper.

(C) 2007 Psychology Press, an imprint of the Taylor \& Francis Group, an Informa business http://www.psypress.com/ecp

DOI: $10.1080 / 09541440601051571$ 
directly from long-term memory, or they might use a nonretrieval (procedural) strategy to solve the problem. Two frequently used procedural strategies are transformation, in which the problem is solved by referring to related operations or by deriving the answer from known facts, and counting, in which participants count one-by-one to reach the correct answer. However, not much is known about the role of working memory across these different arithmetic strategies. More specifically, it is not known whether the execution of all arithmetic strategies does rely on working memory resources. It is not known either whether or not all working memory components are needed across the different arithmetic strategies.

Working memory, as proposed in the model of Baddeley and Hitch (1974), indeed consists of several components: a central executive and two slave systems. ${ }^{1}$ The central executive can be seen as a system with limited capacity that allocates attentional resources to various processes, such as controlling, planning, sequencing, and switching activities. This component also integrates and coordinates the activities of the slave systems, the phonological loop and the visuospatial sketchpad. The phonological loop maintains and manipulates verbal-phonological information, whereas the visuospatial sketchpad maintains and manipulates visuospatial information. The phonological loop further consists of two components: an active subvocal rehearsal process and a passive, phonologically based store.

Previous studies showed that the central executive is always needed to solve simple arithmetic problems (de Rammelaere, Stuyven, \& Vandierendonck, 1999, 2001; de Rammelaere \& Vandierendonck, 2001; Deschuyteneer \& Vandierendonck, 2005a, 2005b; Deschuyteneer, Vandierendonck, \& Muyllaert, 2006; Deschuyteneer, Vandierendonck, \& Coeman, 2007; Hecht, 2002; Lemaire, Abdi, \& Fayol, 1996; Seitz \& Schumann-Hengsteler, 2000, 2002; Seyler, Kirk, \& Ashcraft, 2003). Note that simple arithmetic problems encompass all problems with correct answers up to 20 (e.g., $4+8,13-6$ ), as opposed to complex-arithmetic problems, which encompass more multidigit problems (e.g., $36+72,125-46$ ). The role of the phonological loop in simple arithmetic is less clear, however. DeStefano and LeFevre (2004) note that the role of this working memory component may depend on several factors, such as educational experience and the operation studied. Indeed, most studies with western participants did not observe a significant role of the phonological loop in solving simple addition or multiplication problems (e.g., de Rammelaere et al., 1999, 2001; Seitz \& Schumann-Hengsteler, 2000; but see Lemaire et al., 1996), whereas at least one study with East-Asian participants did observe a significant role of the phonological loop in solving

\footnotetext{
${ }^{1}$ More recently, a third slave system was proposed by Baddeley (2000), namely the episodic buffer. This system integrates information in both other slave systems with information from longterm memory.
} 
simple multiplication problems but not in solving simple subtraction problems (Lee \& Kang, 2002).

What has been neglected in the aforementioned studies, however, is the fact that people use several strategies to solve simple arithmetic problems (e.g., Hecht, 1999; LeFevre et al., 1996a, 1996b). Consequently, the issue of working memory involvement across different arithmetical strategies has scarcely been investigated. To our knowledge, only Hecht (2002) and Seyler et al. (2003) have published research on this topic. In Hecht (2002), participants had to verify simple addition equations (e.g., $4+3=8$ ) under no-load conditions and conditions in which the central executive or phonological loop were loaded. After each trial, participants had to report which strategy they had used. As the pattern of strategy selection (i.e., percentages of chosen strategies) was comparable between no-load and working memory load conditions, Hecht concludes that phonological or executive working memory loads do not influence strategy selection. Strategy efficiency (i.e., solution times of the strategies), however, was impaired by reduced availability of working memory resources. More precisely, Hecht observed that all strategies (i.e., retrieval, transformation, and counting) were slowed down under executive working memory loads, whereas only the counting strategy was slowed down under phonological working memory loads. Based on regression analyses, however, Hecht concludes that retrieval does not rely on the central executive, whereas the counting strategy would rely on both the central executive and the phonological loop.

In Seyler et al. (2003), participants had to solve simple subtraction problems while their working memory was loaded by means of a task in which two-, four-, or six-letter strings had to be remembered. As subtraction performance was slower and more erroneous when participants' working memory was loaded, Seyler et al. conclude that the processing of subtraction facts relies heavily on working memory. Otherwise stated, the strategy efficiency decreased under working memory load, and this was especially the case for participants with low working memory spans. Moreover, Seyler et al. observed that working memory was more involved in procedural strategies than in direct memory retrieval. Although Seyler et al. do not report specific data about the secondary task they used, it may be assumed that the task was primarily loading the phonological loop, and to a lesser extent the central executive.

Based on the studies by Hecht (2002) and Seyler et al. (2003), one could conclude that executive and phonological working memory components are used in procedural strategies but not in direct memory retrieval. However, it is difficult to draw strong conclusions from these studies since (a) Hecht used an addition verification task (e.g., $8+5=12$ ?), whereas Seyler et al. used a subtraction production task (e.g., $12-5=$ ?); (b) Hecht loaded working 
memory phonologically and executively, whereas it is unclear which working memory components were loaded by the secondary task used by Seyler et al.; and (c) in both Hecht's and Seyler et al.'s studies participants were always free to choose the strategy they wanted, which may have biased strategy efficiency data, as explained further in this paper.

Although Hecht (2002) and Seyler et al. (2003) have already addressed the role of working memory in simple arithmetic strategies, the current study was designed to achieve additional insight. First, in the current study, both addition and subtraction problems on which participants had to produce the correct answer themselves (i.e., production tasks) were used. Verification strategies indeed differ from strategies used in production tasks (e.g., Campbell \& Tarling, 1996; Krueger \& Hallford, 1984; Lemaire \& Fayol, 1995; Zbrodoff \& Logan, 1990). The face validity is also larger in production tasks than in verification tasks, as they are more frequently used in daily life. Moreover, solving simple subtraction problems in adults received little attention up until now (but see Barrouillet \& Fayol, 1998; Campbell \& Xue, 2001; Deschuyteneer, Vandierendonck, \& Coeman, 2007; Geary, Frensch, \& Wiley, 1993; Seyler et al., 2003).

Second, we wanted to clarify the role of both executive and phonological working memory components in simple arithmetic strategies. As the role of the visuospatial sketchpad in mental arithmetic is still unclear (e.g., DeStefano \& LeFevre, 2004), it was decided not to include this working memory component in the current project. The phonological loop was further subdivided in its two components (the active rehearsal process and the passive phonological store), and the role of both components was investigated. More specifically, retaining a three- or five-letter string in memory was used to load the active rehearsal process, whereas irrelevant speech was used to load the passive phonological store. Salamé and Baddeley (1982) indeed showed that the passive phonological store is accessed directly by speech while it leaves the active rehearsal process unaffected. It should be noted, however, that tasks loading the active rehearsal process rely on the passive phonological store as well. A continuous choice reaction time task (CRT task), finally, was used to load the central executive. Szmalec, Vandierendonck, and Kemps (2005) have shown that this task interferes with the central executive, while the load on the slave systems is negligible. The CRT task has already been fruitfully adopted in mental-arithmetic studies (e.g., Deschuyteneer \& Vandierendonck, 2005a, 2005b; Deschuyteneer, Vandierendonck, \& Coeman, 2007; Deschuyteneer, Vandierendonck, \& Muyllaert, 2006).

Third, we aimed not only at investigating the role of working memory in strategy efficiency (i.e., how fast are strategies executed?) but also at investigating the role of working memory in strategy selection (i.e., which strategies do people chose?). The choice/no-choice method was used to 
investigate both strategy components (efficiency and selection) independently. As convincingly argued by Siegler and Lemaire (1997), strategy efficiency data obtained in choice conditions might be biased by selection effects. This might have been the case in the studies of Hecht (2002) and Seyler et al. (2003), since these studies only involved a choice condition in which participants were free to choose the strategy they wanted. In the choice/no-choice method, however, each participant is tested under two types of conditions. In the choice condition, participants are free to choose which strategy they want to solve the arithmetic problems. In the no-choice conditions, participants are forced to solve all the problems with one particular strategy. This obligatory use of one particular strategy on all problems precludes selective assignments of strategies to problems and thus yields unbiased strategy efficiency data. There are as many no-choice conditions as there are strategies available in the choice condition. Data obtained in no-choice conditions provide information about strategy efficiency, whereas data gathered in the choice condition provide information about strategy selection. The choice/no-choice method has already been used with arithmetic problems, both in children (e.g., Imbo \& Vandierendonck, in press; Lemaire \& Lecacheur, 2002; Torbeyns, Verschaffel, \& Ghesquière, 2002, 2004a, 2004b, 2005) and in young and older adults (e.g., Imbo, Duverne, \& Lemaire, in press-a; Siegler \& Lemaire, 1997).

Concerning strategy efficiency, it was expected that the central executive would play a role in all strategies, but to a larger extent in procedural strategies than in retrieval. Indeed, several processes which are supposed to rely on executive working memory resources (e.g., the manipulation and calculation of digits) are needed in procedural strategies but not in direct memory retrieval. Anyhow, as accessing long-term memory and selecting the correct answer are processes which might rely on the central executive, effects of an executive working memory load on direct memory retrieval were expected as well. Because temporarily storing intermediate results is only needed in procedural and not in retrieval strategies, it was predicted that the phonological working memory components would play a role in the procedural strategies but not in retrieval. As executive resources fulfil coordination and manipulation functions, whereas phonological resources only fulfil storage functions, we expected that the role of the central executive would be larger than the role of phonological working memory resources. As efficient arithmetic performance not only requests passive storage but also active maintenance of partial results, we further expected that the role of the active phonological rehearsal process would be larger than the role of the passive phonological store. Finally, concerning strategy selection, no effects of working memory load were expected. This hypothesis was based on previous research which did not find load effects on strategy selection either (e.g., Hecht, 2002). 


\section{EXPERIMENT 1: ADDITION}

\section{Method}

Participants. Forty-five first-year psychology students $(5 \mathrm{men}$ and 40 women) at Ghent University participated for course requirements and credits. Their mean age was 20 years and 0 months.

Stimuli. Stimuli of the primary task (i.e., the simple arithmetic task) consisted of simple addition problems that were composed of pairs of numbers between 2 and 9. Problems involving 0 or 1 as an operand or answer (e.g., 5+0) and tie problems (e.g., 3+3) were excluded. All problems crossed 10 (e.g., 3+8). Since commuted pairs (e.g., 9+4 and 4+9) were considered as two different problems, this resulted in 32 addition problems (ranging from $2+9$ to $9+8$ ). Stimuli of the executive secondary task (i.e., the CRT task) consisted of low tones $(262 \mathrm{~Hz})$ and high tones $(524 \mathrm{~Hz})$ that were sequentially presented with an interval of 900 or 1500 ms. Participants had to press the " 4 " on the numerical keyboard when they heard a high tone and the " 1 " when a low tone was presented. The duration of each tone was $200 \mathrm{~ms}$.

Two tasks were used to load the active phonological rehearsal process. Doing so, we wanted to differentiate between the "easier" and "more difficult" tasks used in the past. Indeed, the phonological secondary tasks used in previous studies strongly differed from each other (DeStefano \& LeFevre, 2004). The main difference across both active phonological tasks is the amount of letters that have to be maintained. In the current study, stimuli of the easier task consisted of letter strings of three consonants (e.g., $\mathrm{t} \mathrm{k} \mathrm{x}$ ), whereas stimuli of the more difficult task consisted of letter strings of five consonants (e.g., f s w $\mathrm{r} \mathrm{m}$ ). These consonants were read aloud by the experimenter. The participant had to retain these letters. After three simple arithmetic problems, participants in the three-letter task had to repeat the letters in the correct order. Participants in the five-letter task had to decide whether the order of two adjacent letters that were read aloud by the experimenter was correct (e.g., s w) or incorrect (e.g., w s). The replacement of letter repetition by order verification was based on pilot studies which had showed that repeating all five letters in the five-letter task was too demanding. Replacing letter repetition by order verification made the fiveletter task easier. However, because retaining five letters in memory is more demanding than retaining only three letters in memory; the five-letter task was still more difficult than the three-letter task. Being more difficult, it is possible that the five-letter task would also demand executive working memory resources. The results might give a decisive answer about this issue, and will be discussed further in this paper. For both active phonological 
tasks, a new three- or five-letter string was presented by the experimenter following the response of the participant.

The passive phonological task (irrelevant speech) consisted of dialogues between several people in the Swedish language, which were taken from a compact disc used in language courses. The Swedish dialogues were presented with an acceptable loudness (i.e., around $70 \mathrm{~dB}$ ) through the headphones. None of the participants had any notion of Swedish.

Procedure. Each participant was tested individually in a quiet room for approximately $50 \mathrm{~min}$. The experiment was started with short questions about the age of the participant, his/her study curriculum (i.e., the number of weekly mathematics lessons during the last year of secondary school), and calculator use (i.e., on a rating scale from 1 "never" to 5 "always"). All participants solved the simple arithmetic problems in two sessions: one in which no working memory component was loaded, and one in which one working memory component (the central executive, the passive phonological store, or the active phonological rehearsal process) was loaded. The working memory load differed across participants: For 10 participants the central executive was loaded, for 10 participants the passive phonological store was loaded, for 15 participants the active phonological rehearsal process was loaded with the five-letter task, and for 10 participants the active phonological rehearsal process was loaded with the three-letter task.

For the executive secondary task and the active phonological tasks, single-task data were obtained as well. To this end, participants had to carry out the secondary task for $2 \mathrm{~min}$ in absence of the primary task. An interval of $15 \mathrm{~s}$ was used between the three-letter string and the question to repeat (in the three-letter task) and between the five-letter string and the two-letter probe (in the five-letter task). The secondary-task-only execution took place just before the execution of the primary task in combination with the respective secondary task. This permitted the participants to get used to the secondary-task execution.

Both no-load and load sessions consisted of four conditions: first the choice condition, ${ }^{2}$ and then three no-choice conditions, the order of which was randomised across participants. The choice condition started with comprehensive explanations about the simple arithmetic task and the

\footnotetext{
${ }^{2}$ In both no-load and load session, choice conditions were administered first in order to exclude influence of no-choice conditions on the choice condition. However, as there were two choice conditions (one in the no-load session and one in the load session), order effects still might have occurred. A paired-samples $t$-test indicated a small but significant difference between firstsession (no-load or load) choice RTs and second-session (load or no-load) choice RTs, $t(84)=2.3$, with RTs in the second session being $70 \mathrm{~ms}$ smaller than those in the first one. However, as working memory load was counterbalanced across participants, the bias resulting from this general speeding effect should be small to nonexistent.
} 
strategy reportage. In the choice condition, 6 practice problems and 32 experimental problems were presented. Subsequently, explanations about the no-choice conditions were given, and participants had to solve 32 simple arithmetic problems in each of the three no-choice conditions. After a break of approximately $5 \mathrm{~min}$, the second session was administered. This session also consisted of one-choice condition and three no-choice conditions. The participants who were enrolled in a dual-task session first, now solved the simple arithmetic problems without the secondary task, whereas this order was reversed for the other half of the participants.

A trial started with a fixation point for $500 \mathrm{~ms}$. Then the arithmetic problem appeared in the centre of the screen. The addition problems were presented horizontally in Arabic format, with the operation sign at the fixation point. The problem remained on screen until the subject responded. Timing began when the stimulus appeared and ended when the response triggered the sound-activated relay. To enable this sound-activated relay, participants wore a microphone, which was activated when they spoke their answer aloud. This microphone was connected to a software clock accurate to $1 \mathrm{~ms}$. On each trial, feedback was presented to the participants, a green "Correct" when their answer was correct, and a red "Fout" when it was not.

In the choice condition, participants were free to choose the strategy they wanted. Trial-by-trial self-reports were used to know which strategy the participants had used. Immediately after solving each problem, they had to report verbally which of the four strategies displayed on the screen they had used (see also Campbell \& Gunter, 2002; Campbell \& Xue, 2001; Kirk \& Ashcraft, 2001; LeFevre et al., 1996b; Seyler et al., 2003): (1) Retrieval: You solve the problem by remembering or knowing the answer directly from memory; (2) Count: You solve the problem by counting a certain number of times to get the answer; (3) Transform: You solve the problem by referring to related operations or by deriving the answer from known facts; (4) Other: You solve the problem by a strategy unlisted here, or you do not know what strategy that you used to solve the problem. These four choices had been extensively explained by the experimenter, and it was emphasised that the presented strategies were not meant to encourage use of a particular strategy.

In the no-choice conditions, participants were requested to use one particular strategy to solve all problems. In no-choice/retrieval, they were asked to retrieve the answer. More specifically, they had to say the answer that first popped into their head. In no-choice/transform, they were asked to transform the problem by making an intermediate step to 10 (e.g., $8+5=$ $8+2+3=10+3=13$ ). Finally, in no-choice/count, they had to count oneby-one (subvocally) until they reached the correct total (e.g., $7+4=8 \ldots$ $9 \ldots 10 \ldots 11)$. After having solved the problem, participants also had to answer with "yes" or "no" whether they had succeeded in using the forced strategy. The answer of the participant, the strategy information, 
and the validity of the trial were recorded online by the experimenter. All invalid trials (e.g., failures of the voice-activated relay) were discarded and returned at the end of the block, which minimised data loss due to unwanted failures.

After the simple arithmetic experiment, all participants completed a paper-and-pencil test of complex arithmetic, the French Kit (French, Ekstrom, \& Price, 1963). The test consisted of two subtests, one page with complex addition problems and one page with complex subtraction and multiplication problems. Participants were given 2 min per page, and were instructed to solve the problems as fast and as accurately as possible. The number of correct answers on both subtests were summed to yield a total score.

\section{Results}

Of all trials $7.47 \%$ was spoiled due to failures of the sound-activated relay. Since all these invalid trials returned at the end of the block, most of them were recovered from data loss, which reduced the trials due to failures of the sound-activated relay to $1.28 \%$. Further, all incorrect trials $(2.41 \%)$, all choice trials on which participants reported having used a strategy "Other" $(0.05 \%)$, and all no-choice trials on which participants failed to use the forced strategy $(11.80 \%)$ were deleted. All data were analysed on the basis of the multivariate general linear model; and all reported results are considered to be significant if $p<.05$, unless mentioned otherwise. To test whether the four subject groups (i.e., loaded by the passive phonological task, the active phonological task with three letters, the active phonological task with five letters, or the executive task) differed from each other, several univariate analyses of variance (ANOVAs) were conducted. A first ANOVA was conducted on the scores on the French Kit and showed that the four groups did not differ in mathematical skill, $F<1$ (means of 28.4, 30.3, 27.8, and 31.9 , respectively). A second ANOVA, conducted on the scores of the calculator-use questionnaire, showed that the four groups did not differ in their reported calculator use, $F<1$ (means of 3.8, 3.4, 3.5, and 3.6, respectively). The last ANOVA, conducted on the amount of arithmetic lessons in the last year of secondary school, showed no group differences either, $F<1$ (means of 3.8, 3.9, 4.5, and 4.6, respectively).

Strategy efficiency. Only the RTs uncontaminated by strategy choices (i.e., no-choice RTs) will be considered, since only these RTs provide clear data concerning strategy efficiency. A $4 \times 2 \times 3$ ANOVA was conducted on correct RTs with working memory component (passive phonological, active phonological with three letters, active phonological with five letters, or 
executive) as between-subjects effect, and load (no load vs. load) and strategy (retrieval, transformation, counting) as within-subjects effects (see Table 1). The main effect of load was significant. RTs were higher under load than under no-load, $F(1,41)=21.72, M S E=83,256$. The main effect of strategy was significant as well, $F(2,40)=175.58, M S E=457,279$, and indicated that RTs differed significantly across strategies, with retrieval being faster than transformation, $F(1,41)=148.64, M S E=80,048$, which was in its turn faster than counting, $F(1,41)=142.05, M S E=649,757$. Load and strategy interacted, $F(2,40)=5.60, M S E=232,424$. Although the effect of load was highly significant for each single strategy, it was larger on counting and transformation than on retrieval, $F(1,41)=6.44$ and $F(1,41)=8.65$, respectively. The effect of load did not differ between transformation and counting, $F(1,41)=1.82, p=.18$. Although the effect of working memory component did not reach significance $(F<1)$, there was a significant interaction between working memory component and load, $F(3,41)=$ 6.89. This interaction showed that the effect of working memory load was significant for the active phonological component as measured by the fiveletter task, $F(1,41)=40.21$, and for the executive component, $F(1,41)=$ 9.73, but not for the passive phonological component $(F<1)$ or the active phonological component as measured by the three-letter task $(F<1)$.

TABLE 1

No-choice RTs (in ms) as a function of load, working memory component, and strategy in Experiment 1 (addition); standard errors are in parentheses

\begin{tabular}{|c|c|c|c|c|c|}
\hline & $\begin{array}{l}\text { Phonological } \\
\text { (passive) }\end{array}$ & $\begin{array}{c}\text { Phonological } \\
\text { (active-3 letters) }\end{array}$ & $\begin{array}{c}\text { Phonological } \\
\text { (active-5 letters) }\end{array}$ & $\begin{array}{c}\text { Central } \\
\text { executive }\end{array}$ & $\begin{array}{c}\text { Mean } \\
\text { (all loads) }\end{array}$ \\
\hline \multicolumn{6}{|l|}{ Retrieval } \\
\hline No load & $849(81)$ & $915(81)$ & $879(66)$ & $809(81)$ & 863 (39) \\
\hline Load & $840(83)$ & $851(83)$ & $1074(67)$ & $940(83)$ & $926(40)$ \\
\hline Mean & 845 (79) & $883(79)$ & $976(64)$ & $874(79)$ & $894(38)$ \\
\hline \multicolumn{6}{|c|}{ Transformation } \\
\hline No load & $1388(120)$ & $1365(120)$ & $1400(98)$ & $1183(120)$ & $1334(57)$ \\
\hline Load & 1357 (149) & 1458 (149) & $1704(121)$ & 1479 (149) & $1499(71)$ \\
\hline Mean & $1373(131)$ & $1412(131)$ & $1552(107)$ & $1331(131)$ & $1417(63)$ \\
\hline \multicolumn{6}{|l|}{ Counting } \\
\hline No load & $2811(223)$ & $2854(223)$ & $2572(182)$ & 2707 (223) & $2736(107)$ \\
\hline Load & $2922(326)$ & $2894(326)$ & $3231(266)$ & $2976(326)$ & $3006(156)$ \\
\hline Mean & $2867(265)$ & $2874(265)$ & $2902(216)$ & $2842(265)$ & $2871(127)$ \\
\hline \multicolumn{6}{|c|}{ All strategies } \\
\hline No load & $1682(109)$ & $1711(109)$ & $1617(89)$ & $1566(109)$ & $1644(52)$ \\
\hline Load & $1706(151)$ & $1735(151)$ & $2003(123)$ & $1789(151)$ & $1811(72)$ \\
\hline Mean & 1695 (126) & 1723 (126) & $1810(103)$ & $1682(126)$ & $1727(60)$ \\
\hline
\end{tabular}


This interpretation was confirmed with separate ANOVAs for each single strategy, which tested the effects of the different working memory loads. The effects of passive phonological loads and active phonological loads (as measured by the three-letter task) were negligible for retrieval, transformation, and counting strategies. The effects of executive loads and active phonological loads (as measured with the five-letter task) were highly significant for all strategies. The ANOVA on all strategies confirmed that, although an executive working memory load affected all strategy RTs, the effect was smaller in retrieval than in transformation, $F(1,41)=5.20$, but did not differ between counting and transformation, $F<1$. Similarly, although an active phonological load (as measured by the five-letter task) affected all strategy RTs, the effect tended to be smaller in retrieval than in transformation, $F(1,41)=$ $3.41, p=.07$, and was smaller in transformation than in counting, $F(1,41)=7.22$.

Strategy selection. In order to investigate effects on strategy selection, a $4 \times 2 \times 3$ ANOVA was conducted on percentages strategy use (in the choice condition), with working memory component as between-subjects effect, and load and strategy as within-subjects effects (see Table 2). All three strategies were used spontaneously by the participants, but the main effect of strategy, $F(2,40)=121.35, M S E=1488$, indicated that the percentage of use varied across strategies. Retrieval (51\%) and transformation $(44 \%)$ were used more frequently than counting $(5 \%), F(1,41)=95.76$, $M S E=950$, and $F(1,41)=67.69, M S E=953$, respectively. There was no difference between the percentage retrieval use and the percentage

TABLE 2

Strategy use in the choice condition (in\%) as a function of load and working memory component for all three strategies in Experiment 1 (addition); standard errors are in parentheses

\begin{tabular}{lccccc}
\hline & $\begin{array}{c}\text { Phonological } \\
\text { (passive) }\end{array}$ & $\begin{array}{c}\text { Phonological } \\
\text { (active-3 letters) }\end{array}$ & $\begin{array}{c}\text { Phonological } \\
\text { (active-5 letters) }\end{array}$ & $\begin{array}{c}\text { Central } \\
\text { executive }\end{array}$ & $\begin{array}{c}\text { Mean } \\
\text { (all loads) }\end{array}$ \\
\hline $\begin{array}{l}\text { Retrieval } \\
\quad \text { No load }\end{array}$ & $71(8)$ & $44(8)$ & $53(7)$ & $38(8)$ & $52(4)$ \\
$\quad$ Load & $64(9)$ & $36(9)$ & $63(8)$ & $39(9)$ & $50(4)$ \\
$\begin{array}{l}\text { Transformation } \\
\quad \text { No load }\end{array}$ & $25(8)$ & $53(8)$ & $39(7)$ & $53(8)$ & $42(4)$ \\
$\quad$ Load & $32(9)$ & $58(9)$ & $33(8)$ & $56(9)$ & $45(4)$ \\
Counting & & & & & \\
$\quad$ No load & $4(5)$ & $3(5)$ & $9(4)$ & $9(5)$ & $6(2)$ \\
$\quad$ Load & $4(3)$ & $5(3)$ & $5(3)$ & $5(3)$ & $5(2)$ \\
\hline
\end{tabular}


transformation use, $F<1$. The main effects of load and working memory component did not reach significance, and neither did any interaction (highest $F=1.4$ ).

Secondary task performance. Secondary task performance can be found in Table 3. Performance on the CRT task was significantly faster and more accurate when executed alone than when executed simultaneously with the primary task (choice and no-choice conditions taken together), $F(1,9)=81.47, M S E=1492$, and $F(1,9)=99.98, M S E=187$, respectively. CRT speed was also lower in no-choice/retrieval and nochoice/count than in choice conditions, $F(1,9)=5.54, M S E=1886$, and $F(1,9)=5.35, M S E=2323$, respectively. CRT accuracy did not differ across the choice condition and the three no-choice conditions. When few executive working memory resources are left, performance was thus impaired not only on the primary task but also on the secondary task (cf. Hegarty, Shah, \& Miyake, 2000).

The performance on the active phonological tasks with three and five letters was more accurate when executed alone than when executed simultaneously with the primary task (choice and no-choice conditions taken together), $F(1,9)=14.92, M S E=256$, and $F(1,14)=26.50, M S E=$ 52 , respectively. Performance on the three-letter task did not differ across choice and no-choice conditions, but performance on the five-letter task was more accurate in the no-choice/count condition than in choice and

TABLE 3

RTs (in ms) and accuracies (in\%) on the CRT task and accuracies (in\%) on the active phonological tasks for single-task, choice, and no-choice conditions; standard errors are in parentheses

\begin{tabular}{lcccc}
\hline & $\begin{array}{c}R T \\
\text { CRT task }\end{array}$ & $\begin{array}{c}\text { ACC } \\
\text { CRT task }\end{array}$ & $\begin{array}{c}\text { ACC } \\
\text { 3-letter task }\end{array}$ & $\begin{array}{c}\text { ACC } \\
\text { 5-letter task }\end{array}$ \\
\hline $\begin{array}{l}\text { Experiment 1 (Addition) } \\
\quad \text { Single }\end{array}$ & $503(131)$ & $95(8)$ & $87(20)$ & $92(6)$ \\
$\quad$ Choice & $597(325)$ & $48(14)$ & $70(16)$ & $77(10)$ \\
No-choice/retrieval & $643(355)$ & $46(15)$ & $69(20)$ & $78(13)$ \\
No-choice/transform & $618(347)$ & $49(17)$ & $70(21)$ & $82(13)$ \\
$\quad$ No-choice count & $647(339)$ & $45(22)$ & $76(12)$ & $87(8)$ \\
Experiment 2 (Subtraction) & & & & \\
$\quad$ Single & $516(131)$ & $98(3)$ & $98(5)$ & $88(13)$ \\
Choice & $644(391)$ & $46(9)$ & $65(22)$ & $71(7)$ \\
$\quad$ No-choice/retrieval & $596(360)$ & $49(15)$ & $73(25)$ & $82(17)$ \\
$\quad$ No-choice/transform & $587(352)$ & $49(13)$ & $84(17)$ & $75(8)$ \\
No-choice count & $624(390)$ & $42(12)$ & $72(14)$ & $69(21)$ \\
\hline
\end{tabular}


no-choice/retrieval conditions, $F(1,14)=13.38, M S E=55$, and $F(1,14)=$ 11.17, $M S E=52$, respectively. The other comparisons did not reach significance.

\section{Summary}

The analyses on strategy efficiency showed that not all working memory loads affected the strategies needed to solve simple addition problems. More specifically, performance was affected by an executive working memory load and an active phonological working memory load (as measured by the fiveletter task) but not by a passive phonological working memory load. Further analyses showed that this assertion accounted for all three strategies. Thus, retrieval, transformation, and counting RTs all increased under an executive load and under an active phonological load (i.e., the five-letter task), but not under a passive phonological load. However, procedural strategies were more affected by executive and phonological loads than retrieval strategies were. The analyses on strategy selection showed that retrieval was the most frequently used strategy, followed by transformation. Counting was used rather rarely. There was no effect of working memory load on percentage strategy use. The next experiment, which was similar in design as Experiment 1, investigated the role of the different working memory components in subtraction problems.

\section{EXPERIMENT 2: SUBTRACTION}

\section{Method}

Participants. Forty first-year psychology students $(10$ men and 30 women) at Ghent University participated for course requirements and credits. Their mean age was 19 years and 4 months. None of them had participated in Experiment 1. There were 10 participants in each working memory load condition.

Stimuli and procedure. The 32 subtraction problems were the reverse of the addition problems used in Experiment 1, and thus crossed 10 as well (e.g., $11-3$ ). They ranged from $11-2$ to $17-9$. The procedure was identical to the one used in Experiment 1.

\section{Results}

An amount of $5.78 \%$ of all trials was spoiled due to failures of the soundactivated relay. As these invalid trials returned at the end of the block, the 
amount of trials spoiled due to failures of the sound-activated relay was reduced to $1.08 \%$. Further, all incorrect trials $(5.46 \%)$, all choice trials on which the "other" strategy was chosen $(0.18 \%)$, and all no-choice trials on which participants failed to use the forced strategy $(11.58 \%)$ were deleted. Three univariate analyses of variance (ANOVAs) with loaded working memory component (passive phonological, active phonological with three letters, active phonological with five letters, executive) as between-subjects effect were conducted to test possible differences across the four groups. A first ANOVA, conducted on the scores on the French Kit, showed that the four groups did not differ in mathematical skill, $F<1$ (means of 32.3, 29.7, 30.9 , and 25.6, respectively). A second ANOVA, conducted on the scores of the calculator-use questionnaire, showed that the four groups did not differ in their reported calculator use, $F(3,36)=1.14$ (means of 2.8, 3.6, 3.5, and 3.5 , respectively). The last ANOVA, conducted on the number of weekly arithmetic lessons in the last year of secondary school, showed no differences across groups either, $F(3,36)=1.49$ (means of $4.1,5.0,5.0$, and 5.4, respectively).

Strategy efficiency. A $4 \times 2 \times 3$ ANOVA was conducted on no-choice RTs with working memory component (passive phonological, active phonological with three letters, active phonological with five letters, executive) as between-subjects effect and load (no load vs. load) and strategy (retrieval, transformation, counting) as within-subjects effects (see Table 4). All main effects were significant. RTs were higher under load than under no-load, $F(1$, $36)=23.57, M S E=187,564$. The main effect of working memory component, $F(3,36)=5.96, M S E=1,232,430$, indicated that RTs were higher under executive load than under phonological load (all phonological tasks taken together), $F(1,36)=16.14, M S E=187,565$, whereas there was no difference between the three sorts of phonological load (all $F \mathrm{~s}<1$ ). As a matter of fact, these effects of working memory component were restricted to the load sessions, i.e., the Load $\times$ Working memory component interaction was significant, $F(3,36)=5.53$. More specifically, the effect of load was significant for the executive working memory component, $F(1,36)=34.89$, but not for any of the phonological working memory components (highest $F=2.78$ ). Finally, the main effect of strategy, $F(2,35)=181.76, M S E=915,406$, indicated that RTs differed significantly across strategies, with retrieval RTs being smaller than transformation RTs, $F(1,36)=209.83, M S E=96,614$, which were in their turn smaller than counting RTs, $F(1,36)=156.38$, $M S E=1,283,826$. Load and strategy interacted, $F(2,35)=12.74, M S E=$ $1,407,550$. Although the effect of load was significant for each single strategy, it was larger on transformation than on retrieval, $F(1,36)=15.35$, and larger on counting than on transformation, $F(1,36)=5.78$. 
TABLE 4

No-choice RTs (in ms) as a function of load, working memory component, and strategy in Experiment 2 (subtraction); standard errors are in parentheses

\begin{tabular}{|c|c|c|c|c|c|}
\hline & $\begin{array}{l}\text { Phonological } \\
\text { (passive) }\end{array}$ & $\begin{array}{c}\text { Phonological } \\
\text { (active }-3 \text { letters) }\end{array}$ & $\begin{array}{c}\text { Phonological } \\
\text { (active }-5 \text { letters) }\end{array}$ & $\begin{array}{c}\text { Central } \\
\text { executive }\end{array}$ & $\begin{array}{c}\text { Mean } \\
\text { (all loads) }\end{array}$ \\
\hline \multicolumn{6}{|l|}{ Retrieval } \\
\hline No load & $915(75)$ & $1002(75)$ & $1092(75)$ & $1151(75)$ & $1040(37)$ \\
\hline Load & $915(60)$ & $1071(60)$ & $1001(60)$ & $1362(60)$ & $1087(30)$ \\
\hline Mean & $915(63)$ & $1036(63)$ & 1047 (63) & $1256(63)$ & 1064 (32) \\
\hline \multicolumn{6}{|c|}{ Transformation } \\
\hline No load & $1590(106)$ & $1593(106)$ & $1755(106)$ & $1757(106)$ & $1674(53)$ \\
\hline Load & 1658 (121) & $1680(121)$ & $1895(121)$ & 2275 (121) & $1877(60)$ \\
\hline Mean & 1624 (106) & $1637(106)$ & $1825(106)$ & 2016 (106) & 1775 \\
\hline \multicolumn{6}{|l|}{ Counting } \\
\hline No load & $3558(407)$ & 3140 (407) & 3781 (407) & 4455 (407) & 3734 (203) \\
\hline Load & 4049 (394) & $3453(394)$ & $3981(394)$ & $5708(394)$ & 4298 (197) \\
\hline Mean & 3804 (371) & $3297(371)$ & 3881 (371) & $2082(371)$ & 4016 (186) \\
\hline \multicolumn{6}{|c|}{ All strategies } \\
\hline No load & 2021 (159) & $1912(159)$ & 2209 (159) & 2454 (159) & $2149(79)$ \\
\hline Load & 2207 (149) & 2068 (149) & $2292(149)$ & 3115 (149) & $2421(74)$ \\
\hline Mean & 2114 (143) & $1990(143)$ & $2251(143)$ & $2785(143)$ & $2285(72)$ \\
\hline
\end{tabular}

The three-way interaction between load, working memory component, and strategy tended to be significant, $F(6,72)=1.98, p=.08$. Separate ANOVAs for each single strategy tested the effects of the different working memory loads. The effect of an executive working memory load was significant for all three strategies, whereas the active phonological load with five letters affected transformation RTs only. The active phonological task with three letters had no effect at all, but counting RTs were significantly affected by the passive phonological task. The ANOVA on all strategies showed that the effect of an executive load was higher in counting than in transformation and higher in transformation than in retrieval. Also important, transformation RTs were still more affected by the executive load than by the active phonological load (as measured with the five-letter task).

Strategy selection. In order to investigate effects on strategy selection, a $4 \times 2 \times 3$ ANOVA was conducted on percentage strategy use (in the choice condition), with working memory component as between-subjects effect and load and strategy as within-subjects effects. As in Experiment 1, all three strategies were used spontaneously by the participants (see Table 5). The main effect of strategy, $F(2,35)=218.59, \quad M S E=1288$, indicated that retrieval $(60 \%)$ was used more often than transformation $(34 \%)$, 
TABLE 5

Strategy use in the choice condition (in\%) as a function of load and working memory component for all three strategies in Experiment 2 (subtraction); standard errors are in parentheses

\begin{tabular}{lccccc}
\hline & $\begin{array}{c}\text { Phonological } \\
\text { (passive) }\end{array}$ & $\begin{array}{c}\text { Phonological } \\
\text { active-3 letters) }\end{array}$ & $\begin{array}{c}\text { Phonological } \\
\text { (active-5 letters) }\end{array}$ & $\begin{array}{c}\text { Central } \\
\text { executive }\end{array}$ & $\begin{array}{c}\text { Mean } \\
\text { (all loads) }\end{array}$ \\
\hline $\begin{array}{l}\text { Retrieval } \\
\quad \text { No load }\end{array}$ & $62(8)$ & $52(8)$ & $70(8)$ & $56(8)$ & $60(4)$ \\
$\quad$ Load & $68(8)$ & $48(8)$ & $74(8)$ & $53(8)$ & $61(4)$ \\
$\quad \begin{array}{l}\text { Transformation } \\
\quad \text { No load }\end{array}$ & $30(8)$ & $45(8)$ & $23(8)$ & $39(8)$ & $34(4)$ \\
$\quad$ Load & $27(8)$ & $49(8)$ & $16(8)$ & $42(8)$ & $34(4)$ \\
$\begin{array}{l}\text { Counting } \\
\quad \text { No load }\end{array}$ & $8(3)$ & $2(3)$ & $8(3)$ & $5(3)$ & $6(1)$ \\
$\quad$ Load & $4(3)$ & $3(3)$ & $9(3)$ & $5(3)$ & $5(2)$ \\
\hline
\end{tabular}

$F(1,36)=11.64, M S E=2365$, which was in its turn used more frequently than counting $(6 \%), F(1,36)=42.58, M S E=758$. The main effects of load and working memory component did not reach significance, and neither did any interaction (highest $F=1.3$ ).

Secondary task performance. Secondary task performance can be found in Table 3. Performance on the CRT task was significantly faster and more accurate when executed alone than when executed simultaneously with the primary task (choice and no-choice conditions taken together), $F(1,9)=$ $13.84, M S E=5460$, and $F(1,9)=241.47, M S E=88$, respectively. There was no difference in CRT speed across the choice and no-choice conditions, but CRT accuracy was lower in the no-choice/count condition than in no-choice/ retrieval and no-choice/transform conditions, $F(1,9)=4.70, M S E=60$, and $F(1,9)=5.10, M S E=60$, respectively.

Performance on the active phonological tasks with three and five letters was more accurate when executed alone than when executed simultaneously with the primary task (choice and no-choice conditions taken together), $F(1,9)=26.51, M S E=188$, and $F(1,9)=8.48, M S E=162$, respectively. Performance on the three-letter task was also more accurate in the no-choice/transform condition than in choice, no-choice/retrieval, and no-choice/count conditions, $F(1,9)=14.14, M S E=130, F(1,9)=5.31$, $M S E=126, F(1,9)=8.64, M S E=80$, respectively. There were no differences in performance on the five-letter task across the choice condition and the three no-choice conditions. 


\section{Summary}

The results obtained in Experiment 1 were generalised to subtraction problems, since participants' performances were shown to be affected by an executive working memory load. An active phonological working memory load (as measured by the five-letter task) affected performance as well, albeit only when transformation strategies were used. The present data also showed that a passive phonological load affected counting RTs in subtraction problems. Furthermore, procedural strategies were shown to be more heavily affected by executive and phonological working memory loads than retrieval strategies were. Concerning strategy selection, finally, present results showed that retrieval was the most frequently used strategy, followed by transformation, whereas counting was used rather rarely. No effect of working memory load on strategy selection was observed.

\section{GENERAL DISCUSSION}

All strategies (i.e., retrieval, transformation, and counting) were performed less efficiently under an executive working memory load, in both addition and subtraction problems. However, the degree to which the different strategies were affected differed. As the effects of an executive working memory load were significantly smaller on retrieval RTs than on procedural RTs, we might conclude that the direct memory retrieval required rather few executive working memory resources, whereas the procedural strategies counting and transformation required substantial amounts of executive working memory resources. For addition problems, an active phonological load (the five-letter task) affected both retrieval and procedural RTs, but to a larger extent the latter than the former. For subtraction problems in contrast, an active phonological load affected transformation RTs only. Finally, a passive phonological load only affected RTs when counting was used to solve subtraction problems.

To summarise, executive working memory resources played a role in retrieval and procedural efficiency. Active phonological working memory resources played a role in procedural efficiency under some conditions but were unrelated to retrieval efficiency. However, these conclusions should be treated with caution. One has to keep in mind that only one measure of arithmetic strategy efficiency was examined, namely speed. Accuracy was not included because error rates were very low. The results on strategy efficiency obtained in the current study thus concern strategy speed and not strategy accuracy. More specifically, if participant's performance was slowed down by a specific working memory load, we can conclude that this specific working memory component was needed to solve simple arithmetic 
problems quickly. Whether or not this working memory component is needed to solve simple arithmetic problems accurately remains an open question that future research might resolve. It is, however, difficult to use adults' simple arithmetic accuracy data, as error rates are usually very low. In the following, we address the question of which functions the central executive and the phonological loop might fulfil in simple arithmetic.

\section{The role of the central executive}

An executive working memory load affected both retrieval and procedural RTs. In procedural strategies, executive working memory resources are needed to select and implement the appropriate heuristics when the solution is not directly available through retrieval, and to perform the calculations required for mental arithmetic (e.g., Ashcraft, 1995; Imbo, Vandierendonck, \& de Rammelaere, 2007; Imbo, Vandierendonck, \& Vergauwe, in press-b; Logie, Gilhooly, \& Wynn, 1994). The manipulation of interim results during calculation would also be controlled by the central executive (Fürst \& Hitch, 2000). The fact that the central executive is needed to monitor the number just said and the next count (e.g., Case, 1985; Hecht, 2002; Logie \& Baddeley, 1987) may explain why counting needed even more executive resources than transformation did. Keeping track of counted and to-be-counted items and keeping track of one's progress in a counting sequence indeed places demands on the central executive (Ashcraft, 1995).

The significant effect of an executive working memory load on retrieval RTs implies a possible role for the central executive in memory retrieval. This result is in agreement with results obtained recently by Barrouillet, Bernardin, and Camos (2004), who observed that cognitive resources are needed to perform even the simplest retrievals of overlearned knowledge from long-term memory. However, whether or not the central executive is needed in direct memory retrieval remains a debated topic. Retrieving an answer form long-term memory is composed of two processes. First, several candidate answers - which are represented in an interrelated network of associative links in long-term memory - are automatically activated (e.g., Ashcraft, 1992; Campbell, 1995). Second, one of these answers should be selected as the correct one. One may question whether these processes need executive working memory resources to be executed.

It has been suggested that the interaction between working memory and long-term memory is one of the functions of the central executive (e.g., Baddeley, 1996). If the central executive indeed plays a crucial role in the activation of information in long-term memory, then it is very likely that people with reduced working memory space (either by a low working memory capacity, by a state in which working memory is loaded, or by a 
physiological cause) will experience difficulties in fact retrieval (e.g., Ashcraft, 1995; Conway \& Engle, 1994; Kaufman, 2002). Consequently, insufficient activation of the correct problem-answer association may slow down retrieval processes (Ashcraft, 1995).

The second process, choosing one answer as the correct one, may also load executive working memory resources. Deschuyteneer and colleagues (Deschuyteneer \& Vandierendonck, 2005a, 2005b; Deschuyteneer, Vandierendonck, \& Coeman, 2006a; Deschuyteneer, Vandierendonck, \& Muyllaert, 2006b), for example, showed that the executive working memory functions "response selection" and "inhibition" are important constituents to solve simple arithmetic problems. Because retrieving a correct answer to an arithmetic problem involves selecting this answer and inhibiting several similar answers (or "neighbours"), executive working memory resources are needed to resolve this competition between the correct answer and its neighbours, and to select the correct response.

In spite of these explanations, the question whether the elementary process of fact retrieval does rely on the central executive is still a debated topic. Some authors do believe that executive working memory functions are needed (e.g., Ashcraft, 1995; Baroody, 1994; de Rammelaere \& Vandierendonck, 2001; Lemaire et al., 1996; Seitz \& Schumann-Hengsteler, 2000, 2002), whereas others don't. Hecht (2002), for example, maintains that retrieval does occur automatically (i.e., without relying on any working memory component), even though he observed slower retrieval times when working memory was executively loaded than when it was not loaded. Such effects could indeed also be due to general processes such as comparison and decision effects. In their review, DeStefano and LeFevre (2004) also defend that the use of the central executive in retrieval is tied to general attentional requirements of the task. Although present results do not resolve this ongoing discussion, they provide some guidelines for further research. A more detailed analysis of different executive working memory functions and different arithmetic strategies might be an interesting line for future studies. A combination of the choice/no-choice method and various secondary tasks loading different executive working memory functions would be an excellent methodology for such a study.

\section{The role of the phonological loop}

The phonological task with five letters, which loaded the active phonological rehearsal process, affected the retrieval strategy in the addition experiment but not in the subtraction experiment. The phonological task with five letters also affected procedural strategies, although 
the effect of this task did not reach significance when counting was used to solve subtraction problems. The active rehearsal process may indeed play several roles in arithmetic procedures, such as keeping track of running totals and temporarily storing intermediate or partial results (e.g., Ashcraft, 1995; Heathcote, 1994; Imbo et al., 2007; Logie \& Baddeley, 1987; Logie et al., 1994; Seitz \& Schumann-Hengsteler, 2002). In the addition experiment, the role of the active phonological rehearsal process was even more important in counting than in transformation, which is in agreement with previous studies in which counting processes were investigated in a more direct manner (e.g., counting of dots). Logie and Baddeley (1987), for example, observed that counting processes were significantly disrupted by phonological working memory loads. Camos and Barrouillet (2004) observed longer counting times under a phonological working memory load (maintaining five items in memory) as well. Logie and Baddeley (1987, p. 331) further state that mental counting involves "subvocal articulation of numbers in the counting sequence", whereas Ashcraft (1995) concludes that the phonological loop would be especially involved in counting, given the phonological basis of the oneby-one incrementing process. It is not clear why no significant effects of the active phonological task with three letters were observed. The most plausible explanation is that retaining three letters in memory was not demanding enough to affect the arithmetic performance. Otherwise stated, although retaining three letters in memory must have loaded the active subvocal rehearsal process, there must have been enough space left to retain digits in memory as well (see also Baddeley \& Hitch, 1974).

The passive phonological store (which was loaded by irrelevant speech) was needed when counting was used to solve subtraction problems. This observation is consistent with the assertion that the passive phonological store is used to continually register the running total obtained by the subsequent counting steps. This continued registration of the running total was needed in counting down processes $(9 \ldots 8 \ldots 7)$, but not in counting up processes $(7 \ldots 8 \ldots 9)$, however. This dissociation might be caused by the fact that counting up is overlearned and occurs rather automatically, as opposed to counting down. Indeed, counting down is contraintuitive and people may need to register each count to preclude themselves from forgetting which is the current digit in the counting sequence. Consequently, in the passive phonological store the irrelevant speech (which gains direct access to the store) might have affected the subvocal articulation of each digit. A significant role of the passive phonological store in counting has been observed by Logie and Baddeley (1987) as well.

The significant role of the active rehearsal process (as measured by the active phonological task with five letters) in retrieval strategies was rather 
unexpected, because there is no specific reason to assume that phonological working memory resources are needed in direct memory retrieval. We propose that this result might have been caused by a methodological artifact of our study. More specifically, because maintaining five letters in memory is quite hard, executive functions might have come into play as well, e.g., to compare old with new information and to decide whether the letters are similar or not. The active phonological task with five letters may thus not have been a purely phonological task. The lower retrieval efficiency under the active phonological task with five letters can then be explained by a feature of the design, and not by a significant role of the rehearsal process in retrieval strategies.

Further research is needed to investigate which secondary tasks are most suited to study the role of phonological working memory resources in simple arithmetic performance. Researchers should search for a task in which phonological items should be retained in memory for a certain period (i.e., more than $2 \mathrm{~s}$; otherwise passive phonological resources may fulfil the task). The amount of items to be held in memory should not be exaggerated either, since overloading the rehearsal process may call executive processes into play. The present results suggest that a memory load of three letters is somewhat too small whereas a memory load of five letters would already overload the active rehearsal process.

\section{CONCLUSION}

The present results showed that retrieval, transformation, and counting strategies are slowed down by an executive working memory load. Efficient strategic performance might thus rely on executive resources. Procedural strategies were also slowed down by an active phonological load, whereas only counting efficiency was affected by a passive phonological load. Finally, strategy selection was not affected by any working memory load. Future research might elaborate on these results and (a) investigate which executive functions (e.g., inhibition, memory updating, response selection, ...) are needed in efficient strategic performance, (b) investigate whether or not working memory is needed in other aspects of strategic performance (e.g., strategy accuracy, strategy adaptivity, ...), and (c) test whether the results obtained in the current study generalise to other operations and/or more complex arithmetic problems. 


\section{REFERENCES}

Ashcraft, M. H. (1992). Cognitive arithmetic: A review of data and theory. Cognition, 44, 75-106.

Ashcraft, M. H. (1995). Cognitive psychology and simple arithmetic: A review and summary of new directions. Mathematical Cognition, 1, 3-34.

Baddeley, A. (2000). The episodic buffer: A new component of working memory? Trends in Cognitive Sciences, 4, 417-423.

Baddeley, A. D. (1996). Exploring the central executive. Quarterly Journal of Experimental Psychology, 49A, 5-28.

Baddeley, A. D., \& Hitch, G. J. (1974). Working memory. In G. Bower (Ed.), The psychology of learning and motivation (Vol. 8, pp. 47-90). New York: Academic Press.

Baroody, A. J. (1994). An evaluation of evidence supporting fact-retrieval models. Learning and Individual differences, 6, 1-36.

Barrouillet, P., Benardin, S., \& Camos, V. (2004). Time constraints and resource sharing in adults' working memory span. Journal of Experimental Psychology: General, 133, 83-100.

Barrouillet, P., \& Fayol, M. (1998). From algorithmic computing to direct retrieval: Evidence from number and alphabetic arithmetic in children and adults. Memory and Cognition, 26, 355-368.

Camos, V., \& Barrouillet, P. (2004). Adult counting is resource demanding. British Journal of Psychology, 95, 19-30.

Campbell, J. I. D. (1995). Mechanisms of simple addition and multiplication: A modified networkinterference theory and simulation. Mathematical Cognition, 1, 121-164.

Campbell, J. I. D., \& Gunter, R. (2002). Calculation, culture, and the repeated operand effect. Cognition, 86, 71-96.

Campbell, J. I. D., \& Tarling, D. P. M. (1996). Retrieval processes in arithmetic production and verification. Memory and Cognition, 24, 156-172.

Campbell, J. I. D., \& Xue, Q. (2001). Cognitive arithmetic across cultures. Journal of Experimental Psychology: General, 130, 299-315.

Case, R. (1985). Intellectual development: Birth to adulthood. San Diego, CA: Academic Press.

Conway, A. R. A., \& Engle, R. W. (1994). Working memory and retrieval: A resource-dependent inhibition model. Journal of Experimental Psychology: General, 123, 354-373.

De Rammelaere, S., Stuyven, E., \& Vandierendonck, A. (1999). The contribution of working memory resources in the verification of simple arithmetic sums. Psychological Research, 62, $72-77$.

De Rammelaere, S., Stuyven, E., \& Vandierendonck, A. (2001). Verifying simple arithmetic sums and products: Are the phonological loop and the central executive involved? Memory and Cognition, 29, 267-273.

De Rammelaere, S., \& Vandierendonck, A. (2001). Are executive processes used to solve simple mental arithmetic production tasks? Current Psychology Letters: Behaviour, Brain and Cognition, 5, 79-89.

Deschuyteneer, M., \& Vandierendonck, A. (2005a). Are "input monitoring" and "response selection" involved in solving simple mental arithmetical sums? European Journal of Cognitive Psychology, 17, 347-370.

Deschuyteneer, M., \& Vandierendonck, A. (2005b). The role of "response selection" and "input monitoring" in solving simple arithmetical products. Memory and Cognition, 33, 1472-1483.

Deschuyteneer, M., Vandierendonck, A., \& Coeman, P. (2007). Exploring the role of different executive processes in solving simple mental arithmetical subtractions and divisions. Manuscript submitted for publication.

Deschuyteneer, M., Vandierendonck, A., \& Muyllaert, I. (2006). Does solution of mental arithmetic problems such as $2+6$ and $3 \times 8$ rely on the process of "memory updating"? Experimental Psychology, 53, 198-208. 
DeStefano, D., \& LeFevre, J.-A. (2004). The role of working memory in mental arithmetic. European Journal of Cognitive Psychology, 16, 353-386.

French, J. W., Ekstrom, R. B., \& Price, I. A. (1963). Kit of reference tests for cognitive factors. Princeton, NJ: Educational Testing Service.

Fürst, A. J., \& Hitch, G. J. (2000). Separate roles for executive and phonological components of working memory in mental arithmetic. Memory and Cognition, 28, 774-782.

Geary, D. C., Frensch, P. A., \& Wiley, J. G. (1993). Simple and complex mental subtraction: Strategy choice and speed-of-processing differences in younger and older adults. Journal of Experimental Child Psychology, 47, 175-192.

Heathcote, D. (1994). The role of visual-spatial working memory in the mental addition of multidigit addends. Cahiers de Psychologie Cognitive, 13, 207-245.

Hecht, S. A. (1999). Individual solution processes while solving addition and multiplication facts in adults. Memory and Cognition, 27, 1097-1107.

Hecht, S. A. (2002). Counting on working memory in simple arithmetic when counting is used for problem solving. Memory and Cognition, 30, 447-455.

Hegarty, M., Shah, P., \& Miyake, A. (2000). Constraints on using the dual-task methodology to specify the degree of central executive involvement in cognitive tasks. Memory and Cognition, 28, 376-385.

Imbo, I., Duverne, S., \& Lemaire, P. (in press-a). Working memory, strategy execution, and strategy selection in mental arithmetic. Quarterly Journal of Experimental Psychology.

Imbo, I., \& Vandierendonck, A. (in press). The role of the phonological loop and the central executive in simple-arithmetic strategies. European Journal of Cognitive Psychology.

Imbo, I., Vandierendonck, A., \& de Rammelaere, S. (2007). The role of working memory in the carry operation of mental arithmetic: Number and value of the carry. Quarterly Journal of Experimental Psychology, 60, 709-732.

Imbo, I., Vandierendonck, A., \& Vergauwe, E. (in press-b). The role of working memory in carrying and borrowing. Psychological Research.

Kaufman, L. (2002). More evidence for the role of the central executive in retrieving arithmetic facts: A case study of severe developmental dyscalculia. Journal of Clinical and Experimental Neuropsychology, 24, 302-310.

Kirk, E. P., \& Ashcraft, M. H. (2001). Telling stories: The perils and promise of using verbal reports to study math strategies. Journal of Experimental Psychology: Learning, Memory, and Cognition, 27, 157-175.

Krueger, L. E., \& Hallford, E. W. (1984). Why $2+2=5$ looks so wrong: On the odd-even rule in sum verification. Memory and Cognition, 12, 171-180.

Lee, K.-M., \& Kang, S.-Y. (2002). Arithmetic operation and working memory: Differential suppression in dual tasks. Cognition, 83, B63-B68.

LeFevre, J.-A., Bisanz, J., Daley, K. E., Buffone, L., Greenham, S. L., \& Sadesky, G. S. (1996a). Multiple routes to solution of single-digit multiplication problems. Journal of Experimental Psychology: General, 125, 284-306.

LeFevre, J.-A., Sadesky, G. S., \& Bisanz, J. (1996b). Selection of procedures in mental addition: Reassessing the problem size effect in adults. Journal of Experimental Psychology: Learning, Memory, and Cognition, 22, 216-230.

Lemaire, P., Abdi, H., \& Fayol, M. (1996). The role of working memory resources in simple cognitive arithmetic. European Journal of Cognitive Psychology, 8, 73-103.

Lemaire, P., \& Fayol, M. (1995). When plausibility judgments supersede fact retrieval: The example of the odd-even effect on product verification. Memory and Cognition, 23, 34-48.

Lemaire, P., \& Lecacheur, M. (2002). Children's strategies in computational estimation. Journal of Experimental Child Psychology, 82, 281-304.

Logie, R. H., \& Baddeley, A. D. (1987). Cognitive processes in counting. Journal of Experimental Psychology: Learning, Memory, and Cognition, 13, 310-326. 
Logie, R. H., Gilhooly, K. J., \& Wynn, V. (1994). Counting on working memory in arithmetic problem solving. Memory and Cognition, 22, 395-410.

Salamé, P., \& Baddeley, A. D. (1982). Disruption of short-term memory by unattended speech: Implications for the structure of working memory. Journal of Verbal Learning and Verbal Behavior, 21, 150-164.

Seitz, K., \& Schumann-Hengsteler, R. (2000). Mental multiplication and working memory. European Journal of Cognitive Psychology, 12, 552-570.

Seitz, K., \& Schumann-Hengsteler, R. (2002). Phonological loop and central executive processes in mental addition and multiplication. Psychologische Beiträge, 44, 275-302.

Seyler, D. J., Kirk, E. P., \& Ashcraft, M. H. (2003). Elementary subtraction. Journal of Experimental Psychology: Learning, Memory, and Cognition, 29, 1339-1352.

Siegler, R. S., \& Lemaire, P. (1997). Older and younger adults' strategy choices in multiplication: Testing predictions of ASCM using the choice/no-choice method. Journal of Experimental Psychology: General, 126, 71-92.

Szmalec, A., Vandierendonck, A., \& Kemps, E. (2005). Speeded decision-making as a component of executive functioning. Memory and Cognition, 33, 531-541.

Torbeyns, J., Verschaffel, L., \& Ghesquière, P. (2002). Strategic competence: Applying Siegler's theoretical and methodological framework to the domain of simple addition. European Journal of Psychology of Education, 17, 275-291.

Torbeyns, J., Verschaffel, L., \& Ghesquière, P. (2004a). Strategic aspects of simple addition and subtraction: the influence of mathematical ability. Learning and Instruction, 14, 177-195.

Torbeyns, J., Verschaffel, L., \& Ghesquière, P. (2004b). Strategy development in children with mathematical disabilities: Insights from the choice/no-choice method and the chronologicalage/ability-level-match design. Journal of Learning Disabilities, 37, 119-131.

Torbeyns, J., Verschaffel, L., \& Ghesquière, P. (2005). Simple addition strategies in a first-grade class with multiple strategy instruction. Cognition and Instruction, 23, 1-21.

Zbrodoff, N. J., \& Logan, G. D. (1990). On the relation between production and verification tasks in the psychology of simple arithmetic. Journal of Experimental Psychology: Learning, Memory, and Cognition, 16, 83-97. 
Copyright of European Journal of Cognitive Psychology is the property of Psychology Press (UK) and its content may not be copied or emailed to multiple sites or posted to a listserv without the copyright holder's express written permission. However, users may print, download, or email articles for individual use. 